\title{
A new microconchid tubeworm from the Artinskian (Lower Permian) of central Texas, USA
}

\author{
Mark A. Wilson, Olev Vinn, and Thomas E. Yancey \\ Acta Palaeontologica Polonica 56 (4), 2011: 785-791 doi: http://dx.doi.org/10.4202/app.2010.0086
}

Calcareous tubeworms are common in the Artinskian (Lower Permian) shale and limestone rocks of the Wichita-Albany Group in central Texas. In some units they form small reefs of budding tubes spreading outward from a common origin. These tubular fossils have been traditionally referred to as serpulids, but here we identify them as microconchids (Helicoconchus elongatus gen. et sp. nov.) These microconchids are unusual because of their greatly elongated impunctate tubes with centrally pitted diaphragms. They also show two types of budding: lateral with small daughter tubes that begin as small coils, and binary fission that produced two daughter tubes of equal diameters. These microconchids flourished in shallow marine environments with a fauna dominated by mollusks, echinoids, and foraminifera.

Key words: Tentaculita, Microconchida, reefs, Permian, Texas.

Mark A. Wilson [mwilson@wooster.edu], Department of Geology, The College of Wooster, Wooster, Ohio 44691, USA; Olev Vinn [olev.vinn@ut.ee], Department of Geology, University of Tartu, Ravila 14A, 50411 Tartu, Estonia; Thomas E. Yancey [yancey@geo.tamu.edu], Department of Geology and Geophysics, Texas A \& M University, College Station, Texas 77843, USA.

This is an open-access article distributed under the terms of the Creative Commons Attribution License (for details please see creativecommons.org), which permits unrestricted use, distribution, and reproduction in any medium, provided the original author and source are credited. 
